Systematic Review

\title{
Percutaneous Endoscopic Debridement and Drainage for Spinal Infection: Systemic Review and Meta-Analysis
}

\author{
Yi Mao, MM, Yang Li, MD, and Xingang Cui, MD
}
From: Shandong Provincial
Hospital, Shandong
University, Shandong
Province, China
Address Correspondence: Xingang Cui, MD
Shandong Provincial
Hospital, Shandong University 9677 Jingshi Rd. Jinan, Shandong 250000 , China
E-mail: spine2014@163.com

Disclaimer: There was no external funding in the preparation of this manuscript.

Conflict of interest: Each author certifies that he or she, or a member of his or her immediate family, has no commercial association

(i.e., consultancies, stock ownership, equity interest, patent/licensing arrangements, etc.) that might pose a conflict of interest in connection with the submitted manuscript.

Manuscript received: $11-04-2018$

Accepted for publication: 02-07-2019

Free full manuscript: www.painphysicianjournal. com
Background: Percutaneous endoscopic debridement and drainage (PEDD) has played a vital role in the management of spinal infection; however, limited PEDD results are available to date.

Objectives: The purpose of this systematic review is to examine the existing literature, to give an objective estimate of the outcomes of PEDD using a meta-analytical approach.

Study Design: Meta-analysis and systematic review of retrospective single-arm studies.

Methods: A comprehensive online review was performed in MEDLINE, EMBASE, PubMed, Web of Science, and Cochrane databases from 1980 to October 2018. Eligible studies included the singlearm studies that mentioned PEDD in the management of spinal infection. Pooled event rates for positive bacteria culture, pain control satisfaction, and reoperation were estimated. The complications of PEDD were also recorded.

Results: Nine single-arm PEDD articles (158 patients) were included. The pooled event rate was $82 \%$ (95\% Cl: 75\%-88\%) for positive bacteria culture, $81 \%$ (95\% Cl: $73 \%-87 \%$ ) for pain control satisfaction, and $21 \%(95 \% \mathrm{Cl}: 15 \%-29 \%)$ for reoperation. There are few complications reported in the literature that included transient paresthesia in the affected lumbar segment and local kyphosis.

Limitations: First, all included studies were retrospective series with inherent methodological limitations. Second, the sample size and the number of studies that were found to be eligible was small. In addition, all included studies are single-arm, and further studies are necessary in large randomized controlled trials on comparing the efficacy of conservative therapy, PEDD, and open surgical intervention.

Conclusions: PEDD not only has a high rate of causative-pathogen identification, but also provides satisfactory clinical outcome. Early PEDD intervention in spinal infection is encouraging; however, further studies in large randomized controlled trials on comparing the efficacy of conservative therapy, PEDD, and open surgical intervention are necessary.

Key words: Percutaneous endoscopic debridement and drainage, spinal infection, meta-analysis

Pain Physician 2019: 22:323-330 urrently, the incidence of spinal infection is rising (1) as a consequence of longer life expectancy for patients with chronic debilitating diseases, immunocompromise, human immunodeficiency virus, intravenous drug use, and recent spinal surgery $(2,3)$.

Treatment strategies of spinal infection still remain controversial. Conservative cases seem to be followed by mechanical back pain more often than surgical cases and develop more deformity long term (4). However, surgical intervention is always associated with more complications $(5,6)$, although overall mortality is lower in operated patients (1). Percutaneous endoscopic de- 
bridement and drainage (PEDD), which is coupled with less complications and satisfactory clinical outcome, provides a minimally invasive surgical choice for the treatment of spinal infection (7-12).

The purpose of this manuscript is to use a meta-analytic approach to provide surgeons with an objective estimate of the outcomes of PEDD in the management of spinal infection.

\section{Methods}

\section{Search Strategy}

We performed a comprehensive search for published relevant studies on PEDD in the treatment of spinal infection in MEDLINE, EMBASE, PubMed, Web of Science, and Cochrane databases. Since percutaneous endoscopic discectomy was first employed for treating lumbar disc herniation in the early 1980s (13), the articles from 1980 to October 2018 were searched.

The following key terms were included in our searches: "spinal infection," "spondylodiscitis," "spondylitis," "diskitis," "vertebral osteomyelitis," "spondylodiskitis," "epidural abscess," "paravertebral infection," "endoscopy," "endoscope," and "endoscopic." These keywords searched with various combinations of the operators "AND," "NOT," and "OR." We also chose references cited in the articles and relevant review articles to identify additional studies.

\section{Selection of Studies}

Two review authors ( $\mathrm{YM}$ and $\mathrm{YL}$ ) independently examined all titles and abstracts that met our search terms and reviewed full publications, when necessary. The full texts of all potentially relevant studies were also assessed by 2 reviewers, if necessary. If no agreement could be reached, a third reviewer (XC) made the final decision. We also included observational studies (nonrandomized controlled clinical trials, cohort studies, case-control studies, and retrospective patient series) for an effectiveness analysis.

The eligibility criteria of the included articles were: 1) those that mentioned percutaneous endoscopic surgery for the treatment of spinal infection; 2) a retrospective study, prospective study, cohort study, regardless of sample size; 3) sufficient reported data for extraction and calculation of a recurrence rate with $95 \%$ confidential interval $(\mathrm{Cl}) ; 4)$ in the case of duplicate publication, the most recent or largest study was selected; 5) publications were excluded if the patients underwent thoracoscopic or laparoscopic surgeries, and publications were also excluded if they were review articles, comments, case reports, letters, animal trials, or cadaveric studies; and 6) the language of the included studies was limited to English.

\section{Quality of Data Assessment}

Although the included studies were limited by their retrospective design, all were considered to be of high methodological quality, according to NewcastleOttawa Scale criteria (14). Using a star rating system (range: 0-9 stars), each study was independently judged by 2 authors (YM and $\mathrm{YL}$ ).

\section{Data Extraction}

Two reviewers (YM and $\mathrm{YL}$ ) independently extracted the data of included studies and reached consensus on each item. Data included: 1) authors' names and nationality, publication time, study design, follow-up time, recruitment period, and journal title of each included study; 2) sample size and patient demographic characteristics including age and gender; and 3) the clinical outcome measurement including the length of bacteria culture, operation time, visual analog scale (VAS) or Oswestry Disability Index (ODI) scores, C-reactive protein, elevated erythrocyte sedimentation rate preoperation and postoperation, complications, and reoperation (included re-PEDD and open surgery). These extracted data were rechecked by reviewer XC.

\section{Data Analysis}

A meta-analysis was conducted by using $R$ software version 3.5.1 (R Foundation for Statistical Computing, Vienna, Austria) for all extracted data. The Cochran $Q$ statistic and the $1^{2}$ test were used to assess study heterogeneity. When a significant $\mathrm{Q}$ test $(P<0.10)$ or $\mathrm{I}^{2}>$ $50 \%$ indicated heterogeneity across studies, the DerSimonian and Laird method random effects model was used for meta-analysis, otherwise the Mantel-Haenszel method fixed-effects model was used.

Funnel plots and the Egger's regression test were used to assess for potential publication bias in our meta-analysis. If publication bias was suspected, visual assessment of cumulative forest plots as well as the Classic and Orwin's fail-safe $\mathrm{N}$ tests were used for further assessment. If significant publication bias was found, the Duval and Tweedie trim and fill method was used to adjust for the possible bias. 
PEDD for Spinal Infection

\section{Results}

\section{Eligible Studies and Characteristics of Studies}

Among 1,581 retrieved searched articles, 9 singlearm PEDD articles (7-11,1518) were with a total of 158 included patients (Fig. 1). All of the 9 studies were retrospective. The sample size ranged from 4 to 41 , with a median of 16 . The follow-up of all included studied ranged from 1 to 92 months. The mean age of patients at surgery ranged from 46 to 70.4 years. Among all included studies, 4 articles were from Taiwan, China, and 2 were from Japan. The remaining 3 were from mainland China, South Korea, and India. All relevant information listed and other general characteristics of the included articles were recorded (Appendix 1).

\section{Study Quality}

The results of our Newcastle-Ottawa Scale assessment yielded 3 studies with 6 stars and 6 studies with 7 stars.

\section{Meta-Analysis of Postoperative Outcomes}

\section{Bacteria Culture}

The pooled positive bacteria culture rate was $82 \%$, with $95 \% \mathrm{Cl}$ of $75 \%$ to $88 \%$ in a fixed-effect model. A total of 149 patients were assessed for this outcome and recruited from 8 included articles. No methodological heterogeneity among the

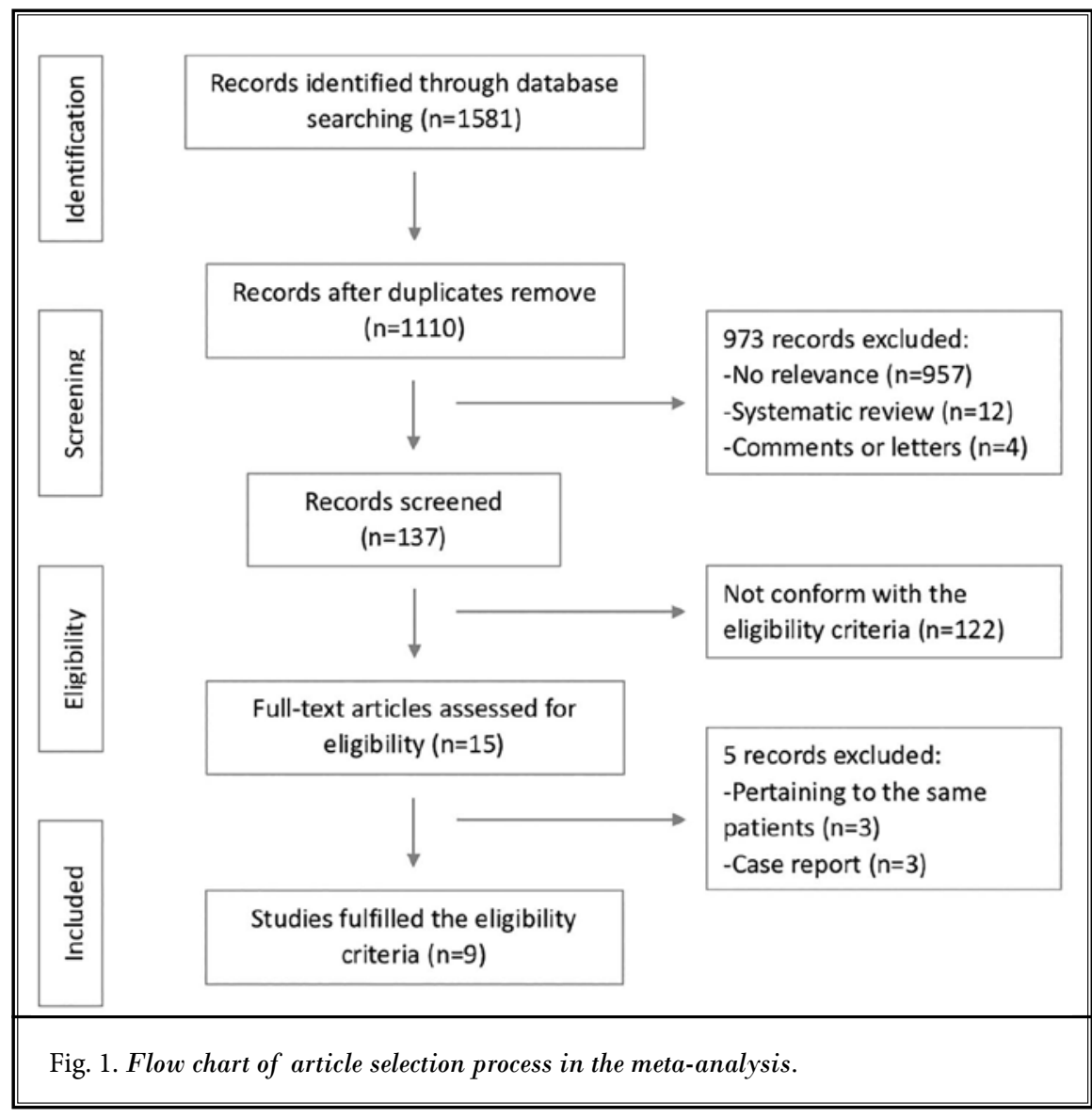

studies $\left(I^{2}=0 ; P=0.78\right)$ was observed (Fig. $\left.2 A\right)$. No serious publication bias was observed in the funnel plot (Fig. 2B).

\section{Pain Control}

The VAS $\leq 3$ or ODI $\leq 50$ at last postoperative follow-up was considered as satisfactory pain control. No pain score was used in the articles, however, patient satisfaction with pain was mentioned and was also included in the study. Finally, 5 articles were scored with VAS, one with ODI, and one article mentioned patient satisfaction with pain. Finally, 7 included articles and 134 patients were selected into the single-arm meta-analysis. The pooled pain control satisfaction rate was $81 \%$, with $95 \% \mathrm{Cl}$ of $73 \%$ to $87 \%$ in a fixed-effect model. No methodological heterogeneity among the studies $\left(I^{2}=0 ; P=0.70\right)$ was observed (Fig. $3 \mathrm{~A})$. No serious publication bias was observed in the funnel plot after using the trim and fill method (Fig. 3B).

\section{Reoperation}

The pooled reoperation rate was $21 \%$, with $95 \% \mathrm{Cl}$ of $15 \%$ to $29 \%$ in a fixed-effect model, and $19 \%$, with $95 \% \mathrm{Cl}$ of $12 \%$ to $29 \%$ in a random-effect model. A total of 158 patients were assessed for this outcome and recruited from 9 included articles. No methodological heterogeneity among the studies $\left(I^{2}=30 \% ; P=0.17\right)$ was observed (Fig. 4A). 

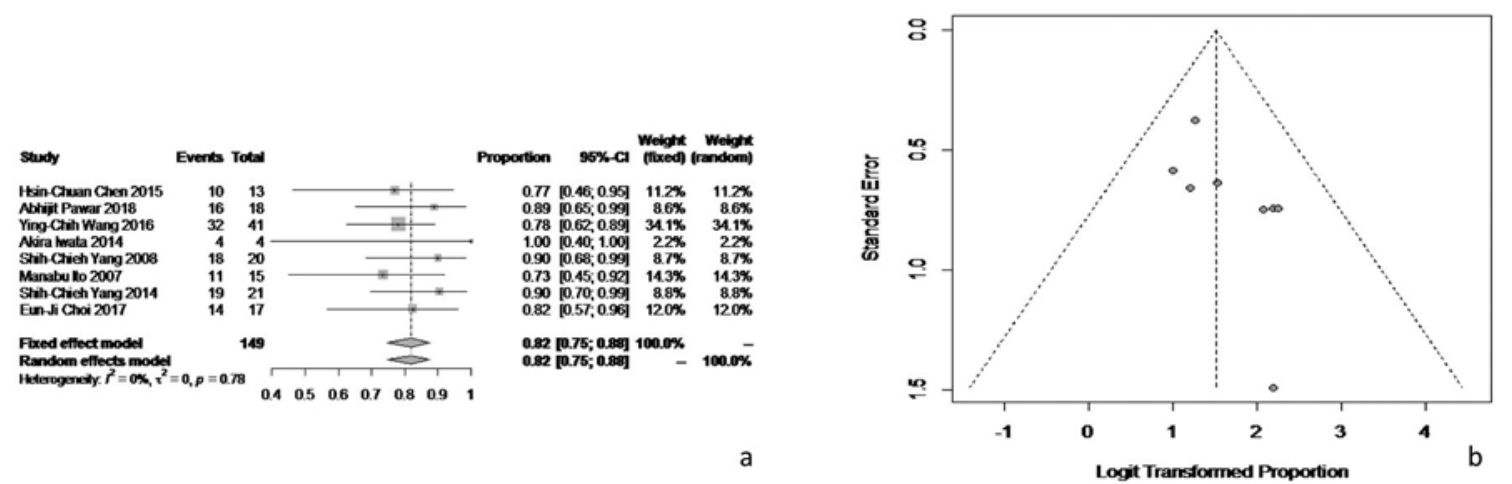

Fig. 2. Forest plot (A) and funnel plot (B) of positive bacteria culture rate. No serious publication bias was observed in the funnel plot.
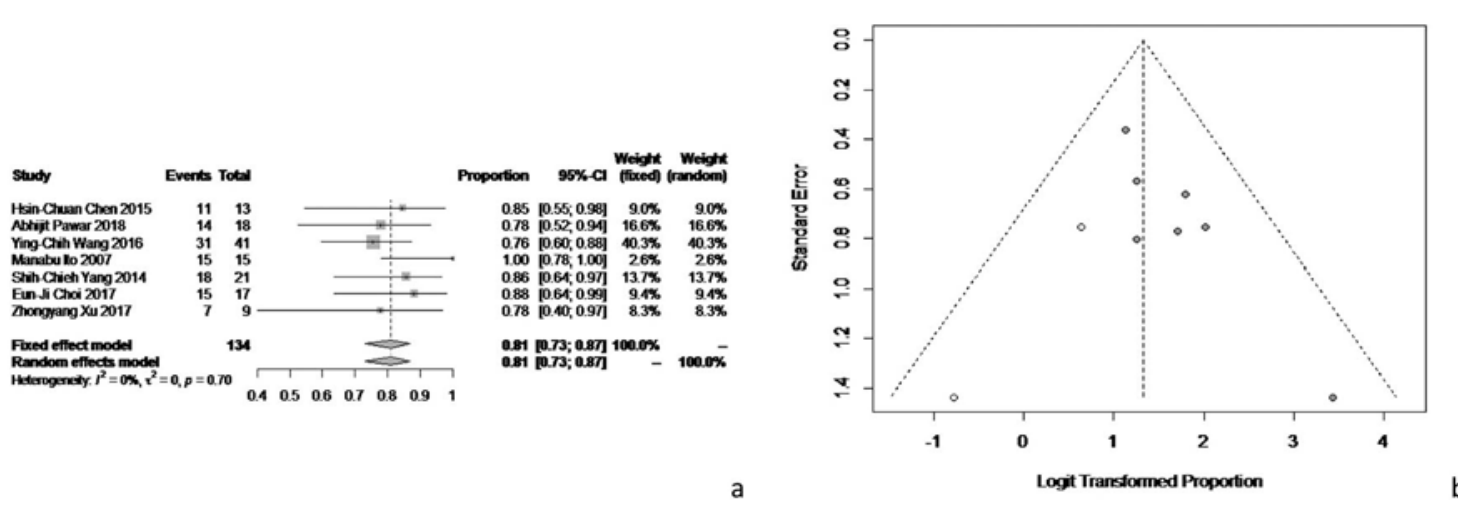

Fig. 3. Forest plot (A) and funnel plot (B) of pain control satisfaction rate. No serious publication bias was observed in the funnel plot after using trim and fill method.
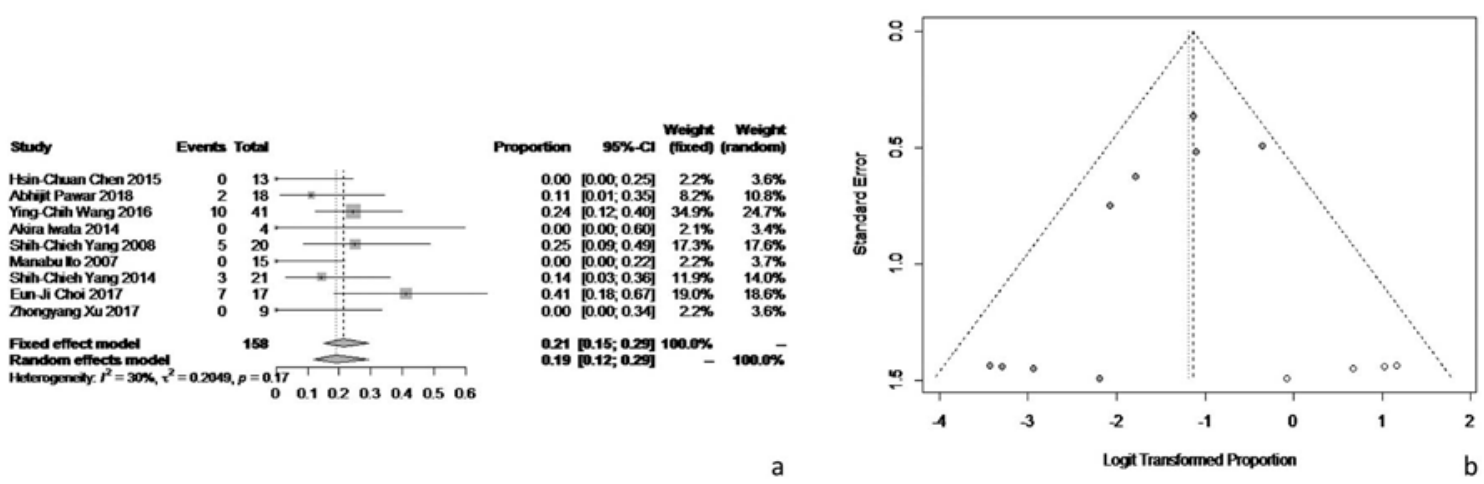

Fig. 4. Forest plot $(A)$ and funnel plot (B) of reoperation rate. There may be publication bias in the funnel plot after using trim and fill method. 
PEDD for Spinal Infection

The funnel plot after using the trim and fill method of the reoperation rate indicated possible mild publication bias (Fig. $4 B)$, which may also be caused by the small sample size or the different parameters and methods in different studies. The sensitivity analysis was performed to determine the robustness of the overall treatment effects because of the small sample size in the included studies. After eliminating the included studies one by one, the sensitivity analysis of reoperation rate was $21 \%$, with $95 \% \mathrm{Cl}$ of $15 \%$ to $29 \%$, which demonstrated the stability of the analysis results (Table 1).

\section{Complications}

There are too few articles that reported the complications to carry out a meta-analysis. Yang et al (12) reported 3 patients with transient paresthesia in the affected lumbar segment. The other complication referred to in the studies $(7,15,19)$ was local kyphosis. Chen et al (7) reported one of 13 patients had a kyphotic change $>$ $10^{\circ}$ at last postoperative follow-up. Ito et al (15) reported 9 of 15 patients had kyphotic deformity, and local kyphosis ranged from $2^{\circ}$ to $25^{\circ}$ with an average of $12^{\circ}$. Fu et al (19) counted the local kyphosis angle of all 6 patients, which ranged from $-15^{\circ}$ to $10^{\circ}$ (average, $1^{\circ}$ ).

Table 2 summarizes the outcomes of the single-arm studies.

\section{Discussion}

This single-arm meta-analyses yield 9 studies with 158 patients who underwent PEDD. The important findings of these analyses were that the pooled event rate of positive bacteria culture, pain control satisfaction, and reoperation was $82 \%, 81 \%$, and $21 \%$, respectively. We also concluded that PEDD that accompanied few complications was relatively safe.

Treatment strategies of spinal infection still remain controversial. Conservative cases seem to be followed by mechanical back pain more often than surgical cases and develop more deformity long term (4).
Table 1. The sensitivity analysis of reoperation rate.

\begin{tabular}{|l|c|c|c|c|}
\hline \multicolumn{1}{|c|}{ Trial } & Proportion & $\mathbf{9 5 \%}$ CI & Tau$^{2}$ & $\mathbf{I}^{\mathbf{2}}$ \\
\hline Omitting Chen et al (7) & 0.2226 & $0.1576-0.3047$ & 0.1533 & $26.6 \%$ \\
\hline Omitting Pawar et al (8) & 0.2269 & $0.1590-0.3129$ & 0.2200 & $32.20 \%$ \\
\hline Omitting Wang et al (9) & 0.2003 & $0.1294-0.2968$ & 0.3757 & $37.40 \%$ \\
\hline Omitting Iwata et al (10) & 0.2181 & $0.1541-0.2991$ & 0.2494 & $37.10 \%$ \\
\hline Omitting Yang et al (11) & 0.2079 & $0.1418-0.2943$ & 0.3283 & $38.20 \%$ \\
\hline Omitting Ito et al (15) & 0.2232 & $0.1580-0.3055$ & 0.1356 & $24.30 \%$ \\
\hline Omitting Yang et al (16) & 0.2263 & $0.1574-0.3141$ & 0.2656 & $35.10 \%$ \\
\hline Omitting Choi et al (17) & 0.1800 & $0.1209-0.2595$ & 0.0015 & $0.30 \%$ \\
\hline Omitting Xu and Zheng (18) & 0.2211 & $0.1564-0.3029$ & 0.1926 & $31.30 \%$ \\
\hline Pooled estimate & 0.2148 & $0.1522-0.2942$ & 0.2049 & $30.50 \%$ \\
\hline
\end{tabular}

Table 2. Outcomes summary of included single-arm studies.

\begin{tabular}{|l|c|c|c|c|c|}
\hline $\begin{array}{c}\text { Pooled } \\
\text { Event } \\
\text { Rate }\end{array}$ & $\begin{array}{c}\text { Number } \\
\text { of } \\
\text { Studies }\end{array}$ & Patients & Percentage & 95\% CI & Heterogeneity \\
\hline $\begin{array}{l}\text { Positive } \\
\text { bacteria } \\
\text { culture }\end{array}$ & 8 & 149 & 0.82 & $0.75-0.88$ & $\mathrm{I}^{2}=0 ; P=0.78$ \\
\hline $\begin{array}{l}\text { Pain control } \\
\text { Satisfaction }\end{array}$ & 7 & 134 & 0.81 & $0.73-0.87$ & $\mathrm{I}^{2}=0 ; P=0.70$ \\
\hline Reoperation & 9 & 158 & 0.21 & $0.15-0.29$ & $\mathrm{I}^{2}=30 \% ; P=0.17$ \\
\hline
\end{tabular}

However, surgical intervention is always associated with more complications, although overall mortality is lower in operated patients (1). PEDD, which is coupled with less complications and satisfactory clinical outcome, provides a minimally invasive surgical choice for the treatment of spinal infection (7-12).

There have been several attempts to treat spinal infections using minimally invasive surgical techniques. Valls et al (20) reported the technique of needle biopsy for vertebral infections in 1984. Yu et al (21) treated osteomyelitis by percutaneous suction aspiration in 2 patients. Staatz et al (22) published the technique of computed tomography (CT)-guided percutaneous catheter drainage in the management of spondylodiscitis abscesses. Then, there was a flood of new technologies including percutaneous transpedicular automated nucleotomy for debridement $(23,24)$, percutaneous transpedicular discectomy and drainage $(25,26)$, and percutaneous drainage and continuous irrigation $(27,28)$. These have been approved as relatively efficient and safe procedures in the management of spinal infection; however, these procedures lack intraoperative virtual images monitoring for debridement of the lesion site. Since percutaneous endoscopic discectomy was first employed for treating uncomplicated herniated discs in the early 1980s (13), numerous minimally invasive percutaneous endoscopic procedures for lumbar 
disc herniation have been developed. Several surgeons attempted to apply percutaneous endoscopic surgery to the management of spinal infections $(15,19,29)$.

The diagnosis of spinal infection is usually delayed before finding a specific neurologic deficit because its onset of symptoms and signs, such as back pain and fever, are insidious and nonspecific (17). Early detection of causative organism is of important significance for the diagnosis and treatment of spinal infection. The most reliable tests for finding the causative organism are histologic examination and cultures of the samples taken from the infection sites. CT-guided biopsy is a less invasive procedure used to obtain specimens for pathogen identification; however, the rate of pathogen identification varies from $30 \%$ to $47 \%$ in most of these studies (11,30-33). Yang et al (11) compared the diagnostic value of $\mathrm{CT}$ guidance with that of endoscope guidance in 52 patients with suspected infectious spondylitis and found that causative bacteria were identified more frequently with percutaneous endoscopy than in CTguided biopsy ( $90 \%$ vs. $47 \%$ ). In our study, the positive bacteria culture rate of PEDD was $82 \%$, well above that of CT-guided biopsy, its basic anastomotic with the Yang et al (11) research. Direct endoscopic observation makes possible the direct collection of sufficient amounts of samples from the infected region for a better possible diagnosis of the causative organism (12). Moreover,
PEDD can effectively eliminate the infected tissues and curette the bony end plates to enhance blood flow at the site of infection, which makes the infiltration of antibiotics to the infected areas more efficient $(9,10,12)$. Therefore, a good clinical result is achieved.

To the best of our knowledge, this study is the first review of the efficacy of PEDD in the management of spinal infection. However, there are several limitations. First, all included studies were retrospective series with inherent methodological limitations. Second, the sample size and the number of studies that were found to be eligible was small. In addition, all included studies are single-arm, and further studies are necessary in large randomized controlled trials on comparing the efficacy of conservative therapy, PEDD, and open surgical intervention.

\section{Conclusions}

This systematic review provides evidence that PEDD not only has a high rate of causative-pathogen identification, but also provides satisfactory clinical outcome. Early PEDD intervention in spinal infection is encouraging; however, further studies in large randomized controlled trials on comparing the efficacy of conservative therapy, PEDD, and open surgical intervention are necessary. 


\begin{tabular}{|c|c|c|c|c|c|c|c|c|c|}
\hline 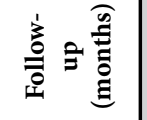 & $\stackrel{n}{\mathfrak{y}}$ & $\triangle$ & $\stackrel{\sim}{\Delta}$ & 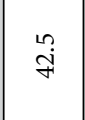 & $\begin{array}{l}\infty \\
\dot{m} \\
\dot{m}\end{array}$ & $\stackrel{\text { li }}{\text { i }}$ & $\vec{m}$ & $m$ & $\tau$ \\
\hline 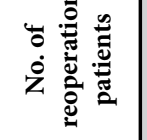 & 0 & $N$ & $\stackrel{9}{1}$ & 0 & in & 0 & $m$ & $m$ & 0 \\
\hline 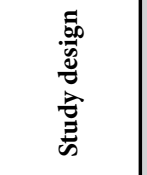 & 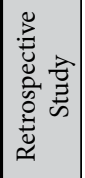 & 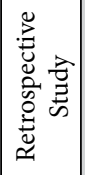 & 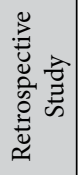 & 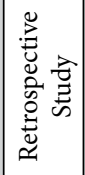 & 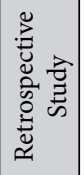 & 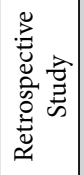 & 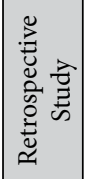 & 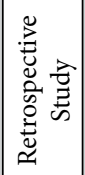 & 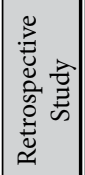 \\
\hline 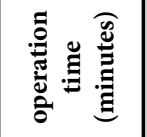 & z̆ & in & 号 & $\mathbb{F}$ & žn & $\stackrel{\infty}{n}$ & 号 & ż & $\tilde{z}$ \\
\hline 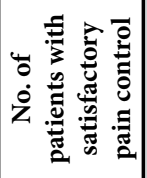 & $=$ & $\exists$ & $\vec{m}$ & 苂 & 苂 & $\stackrel{2}{\rightarrow}$ & $\stackrel{\infty}{-}$ & $\stackrel{2}{2}$ & $n$ \\
\hline 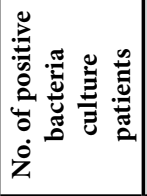 & $\stackrel{9}{1}$ & $\stackrel{?}{0}$ & $\approx$ & $r$ & $\stackrel{\infty}{2}$ & $=$ & $\stackrel{2}{ }$ & $\Xi$ & $\tilde{z}$ \\
\hline 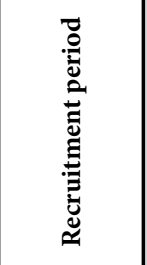 & 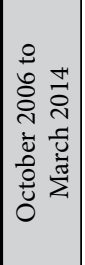 & 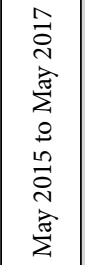 & 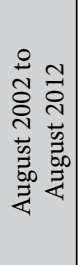 & 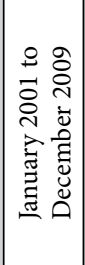 & 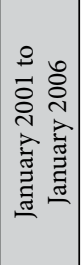 & 号 & 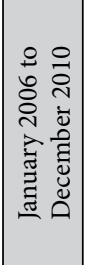 & 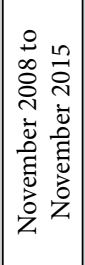 & 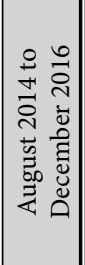 \\
\hline 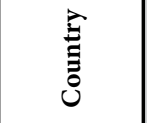 & 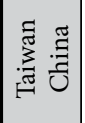 & 㲕 & 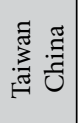 & 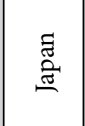 & 氙 & $\begin{array}{l}\text { 䓌 } \\
\text { 胥 }\end{array}$ & 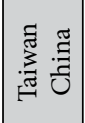 & 苛 & 节 \\
\hline 嵒总 & $\begin{array}{l}0 \\
\dot{b}\end{array}$ & to & 路 & $\begin{array}{l}\infty \\
\text { ì }\end{array}$ & $\tilde{6}$ & 8 & $\begin{array}{l}\text { n } \\
\text { in }\end{array}$ & $\stackrel{+}{\stackrel{2}{R}}$ & ț \\
\hline 离 & $\frac{\infty}{i n}$ & $\frac{\tilde{Z}}{6}$ & $\frac{\text { ลे }}{\pi}$ & 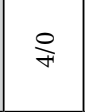 & $\frac{\infty}{\beth}$ & $\stackrel{n}{\varrho}$ & $\stackrel{N}{F}$ & $\stackrel{\varrho}{\Xi}$ & in \\
\hline 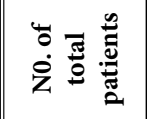 & $\cong$ & $\stackrel{\infty}{\stackrel{1}{2}}$ & $F$ & $r$ & $\stackrel{\text { స }}{\text { s }}$ & $\stackrel{20}{\rightarrow}$ & $\vec{\sim}$ & 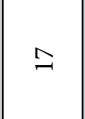 & $a$ \\
\hline 跷 & 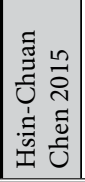 & 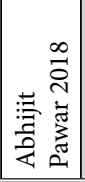 & 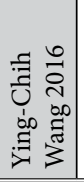 & 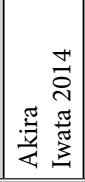 & 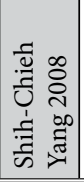 & 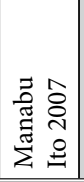 & 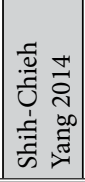 & 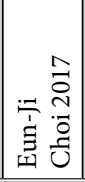 & 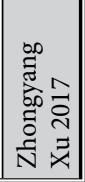 \\
\hline
\end{tabular}




\section{References}

1. Stüer C, Stoffel M, Hecker J, Ringel $F$, Meyer B. A staged treatment algorithm for spinal infections. J Neurol Surg A Cent Eur Neurosurg 2013; 74:87-95.

2. Rui MD, Vaccaro AR. Spinal infection: State of the art and management algorithm. Eur Spine J 2013; 22:2787-2799.

3. Cervan AM, Colmenero Jde D, Del Arco A, Villanueva F, Guerado E. Spondylodiscitis in patients under haemodyalisis. Int Orthop 2012; 36:421-426.

4. Lener S, Hartmann S, Barbagallo GMV, Certo F, Thomé C, Tschugg A. Management of spinal infection: A review of the literature. Acta Neurochir (Wien) 2018; 160:487-496.

5. Lin Y, Li F, Chen W, Zeng H, Chen A, Xiong W. Single-level lumbar pyogenic spondylodiscitis treated with mini-open anterior debridement and fusion in combination with posterior percutaneous fixation via a modified anterior lumbar interbody fusion approach. J Neurosurg Spine 2015; 23:747-753.

6. Viezens L, Schaefer C, Helmers R, Vettorazzi E, Schroeder M, Hansen-Algenstaedt N. Spontaneous pyogenic spondylodiscitis in the thoracic or lumbar spine: A retrospective cohort study comparing the safety and efficacy of minimally invasive and open surgery over a nine-year period. World Neurosurg 2017; 102:18-27.

7. Chen HC, Huang TL, Chen YJ, Tsou HK, Lin WC, Hung $\mathrm{CH}$, Tsai $\mathrm{CH}$, Hsu $\mathrm{HC}$, Chen HT. A minimally invasive endoscopic surgery for infectious spondylodiscitis of the thoracic and upper lumbar spine in immunocompromised patients. Biomed Res Int 2015; 2015:780451.

8. Pawar A, Manwani C, Thete R, Bapat M, Peshettiwar V, Gore S. Endoscopic decompression can be effective for diagnosing and treating tubercular spondylodiskitis with early epidural spinal compression: A retrospective study of 18 cases. Asian Spine J 2018; 12:803-809.

9. Wang YC, Wong CB, Wang IC, Fu TS, Chen $\mathrm{LH}$, Chen WJ. Exposure of prebiopsy antibiotics influence bacteriological diagnosis and clinical outcomes in patients with infectious spondylitis. Medicine 2016; 95:e3343.

10. Iwata A, Ito $M$, Abumi $K$, Sudo $H$, Kotani $Y$, Shono $Y$, Minami A. Fungal spinal infection treated with percutaneous posterolateral endoscopic surgery. J Neurol Surg A Cent Eur Neurosurg 2014; 75:170-176.

11. Yang S, Fu TL, Chen W, Chen WJ, Tu YK. Identifying pathogens of spondylodisci- tis: Percutaneous endoscopy or CT-guided biopsy. Clin Orthop Relat Res 2008; 466:3086.

12. Yang SC, Fu TS, Chen HS, Kao YH, Yu SW, Tu YK. Minimally invasive endoscopic treatment for lumbar infectious spondylitis: A retrospective study in a tertiary referral center. BMC Musculoskelet Disord 2014; 15:105.

13. Hausmann B, Forst R. Nucleoscope. Instrumentarium for endoscopy of the intervertebral disc space. Arch Orthop Trauma Surg 1983; 102:57-59.

14. Stang A. Critical evaluation of the Newcastle-Ottawa scale for the assessment of the quality of nonrandomized studies in meta-analyses. Eur J Epidemiol 2010; 25:603-605.

15. Ito M, Abumi K, Kotani Y, Kadoya K, Minami A. Clinical outcome of posterolateral endoscopic surgery for pyogenic spondylodiscitis: Results of 15 patients with serious comorbid conditions. Spine 2007; 32:200.

16. Yang SC, Chen WJ, Chen HS, Kao YH, Yu SW, Tu YK. Extended indications of percutaneous endoscopic lavage and drainage for the treatment of lumbar infectious spondylitis. Eur Spine J 2014; 23:846-853.

17. Choi EJ, Kim SY, Kim HG, Shon HS, Kim TK, Kim KH. Percutaneous endoscopic debridement and drainage with four different approach methods for the treatment of spinal infection. Pain Physician 2017; 20:E933.

18. Xu Z, Zheng Y. Percutaneous endoscopic debridement and irrigation for thoracic infections. Rev Assoc Med Bras 2018; 64:518-524.

19. Fu TS, Yang SC, Tsai TT, Chen LH, Lai PL, Niu CC, Chen WJ. Percutaneous endoscopic debridement and drainage in immunocompromised patients with complicated infectious spondylitis. Minim Invasive Ther Allied Technol 2010; 19:42-47.

20. Valls J, Ottolenghi CE, Shajowwicz F. Aspiration biopsy in diagnosis of lesions of vertebral bodies. J Am Med Assoc 1984; 136:375-382.

21. Yu WY, Siu C, Wing PC, Schweigel JF, Jetha N. Percutaneous suction aspiration for osteomyelitis. Spine 1991; 16:198-202.

22. Staatz G, Adam GB, Keulers P, Vorwerk D, Günther RW. Spondylodiskitic abscesses: CT-guided percutaneous catheter drainage. Radiology 1998; 208:363-367.

23. Crow WN, Borowski AM, Hadjipavlou AG, Walser EM, Arya S, Calme MB, Amps J, Jensen R, Somisetty S, Alford B, Ad- esokan A. Percutaneous transpedicular automated nucleotomy for debridement of infected discs. J Vasc Interv Radiol 1998; 9:161-165.

24. Onik G, Shang Y, Maroon JC. Automated percutaneous biopsy in postoperative diskitis: A new method. Am J Neuroradiol 1990; 11:391-393.

25. Arya S, Crow WN, Hadjipaviou AG, Nauta HJ, Borowski AM, Vierra LA, Walser E. Percutaneous transpedicular management of discitis. J Vasc Interv Radiol 1996; 7:921-927.

26. Hadjipavlou AG, Katonis PK, Gaitanis IN, Muffoletto AJ, Tzermiadianos MN, Crow W. Percutaneous transpedicular discectomy and drainage in pyogenic spondylodiscitis. Eur Spine ] 2004; 13:707-713.

27. Hanaoka N, Kawasaki Y, Sakai T, Nakamura T, Nanamori K, Nakamura E, Uchida K, Yamada H. Percutaneous drainage and continuous irrigation in patients with severe pyogenic spondylitis, abscess formation, and marked bone destruction. J Neurosurg Spine 2006; 4:374-379.

28. Tofuku K, Koga H, Yone K, Komiya S. Continuous irrigation in pyogenic spondylitis accompanied by iliopsoas abscess. Spine 2007; 15: $\mathrm{E}_{3} 82-\mathrm{E}_{3} 87$.

29. Yang SC, Fu TS, Chen LH, Niu CC, Lai PL, Chen WJ. Percutaneous endoscopic discectomy and drainage for infectious spondylitis. Int Orthop 2007; 31:367-373.

30. Kasalak Ö, Wouthuyzen-Bakker M, Adams HJA, Overbosch J, Dierckx RAJO, Jutte PC, Kwee TC. CT-guided biopsy in suspected spondylodiscitis: Microbiological yield, impact on antimicrobial treatment, and relationship with outcome. Skeletal Radiol 2018; 47:1383-1391.

31. Chong BSW, Brereton CJ, Gordon A, Davis JS. Epidemiology, microbiological diagnosis, and clinical outcomes in pyogenic vertebral osteomyelitis: A 10-year retrospective cohort study. Open Forum Infect Dis 2018; 5:ofyo37.

32. Foreman SC, Schwaiger BJ, Gempt J, Jungmann PM, Kehl V, Delbridge C, Wantia N, Zimmer C, Kirschke JS. MR and CT Imaging to optimize CT-guided biopsies in suspected spondylodiscitis. World Neurosurg 2017; 99:726-734.e7.

33. Chang CY, Simeone FJ, Nelson SB, Taneja AK, Huang AJ. Is biopsying the paravertebral soft tissue as effective as biopsying the disk or vertebral endplate? 10-Year retrospective review of CT-guided biopsy of diskitis-osteomyelitis. AJR Am J Roentgenol 2015; 205:123-129. 